\title{
Credence cues of pork are more important than consumers' culinary skills to boost their purchasing intention
}

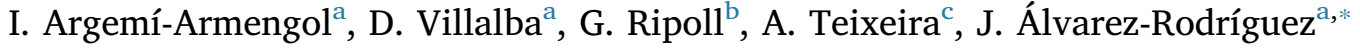 \\ ${ }^{a}$ Universitat de Lleida, Departament de Ciència Animal, Avda. Rovira Roure, 191, 25198 Lleida, Spain \\ ${ }^{\mathrm{b}}$ Centro de Investigación y Tecnología Agroalimentaria de Aragón (CITA)-IA2, Unidad de Producción y Sanidad Animal, Avda. Montañana, 930, 50059 Zaragoza, Spain \\ ${ }^{\mathrm{c}}$ Escola Superior Agrária, Instituto Politécnico de Bragança-Centro de Investigação de Montanha (CIMO), Campus de Santa Apolónia, 5300-253 Bragança, Portugal
}

\section{A R T I C L E I N F O}

\section{Keywords:}

Consumer decision-making

Convenience

Involvement

Pig meat

Portugal

Spain

\begin{abstract}
A B S T R A C T
The role of consumers' culinary skills on purchasing cues of pork, with emphasis on niche demands (outdoor husbandry and/or certified organic), was assessed in cross-country regions of Spain (Catalonia and Aragon) and Portugal (North). A sample of 974 respondents answered an on-line survey with questions regarding consumer purchasing habits, product involvement and intrinsic and credence attributes. They also chose between two contrasting boneless pork loins and express willingness to pay (WTP) for different product scenarios with different pig farm facilities and for organic pork standards. Two optimal segments were identified based on foodrelated habits: 'uninvolved' and 'innovative cook lovers', both similarly balanced across socio-demographics, score for credence attributes or consumer involvement dimensions. Overall mean WTP premium across countries was $11.8 \%$ for marbled pork, $20.0 \%$ for outdoor pork and $24.3 \%$ for organic logo stamp. Credence cues of pork claiming health issues (absence of antibiotics and hormone residues) rather than consumers' culinary skills defined the WTP for niche pork in these regions.
\end{abstract}

\section{Introduction}

Niche pork is characterized by certain attributes which are not found in commodity pork. Organic pork may be considered a type of niche pork, with recognized standards in terms of animal husbandry and meat processing. In general, consumers' attitudes towards organic pork are based on beliefs associated with potentially less risk to their health, improved taste, environmental friendliness and improved welfare of the pigs (Abrams, Meyers, \& Irani, 2010). However, it is also a widespread opinion that the attitudes that consumers express may not be strongly related to their purchase behavior (Grunert, 2006), as mirrored by the low market shares of, for example, organic meat. As an example, the organic swine sector is at present negligible in Spain and Portugal, as it represents only $0.04 \%$ and $0.03 \%$ out of total swine stocks. However, there are other European countries whose organic swine stocks accounts for approximately $2 \%$ out of total swine production (Austria, Denmark, Sweden and France) (Eurostat, 2018). Niche production (and specifically certified organic meat) may experience advancements in the future, and it may be expected that certain customer segments would be willing to pay for a premium for this meat type. However, this issue has not been addressed thoroughly in Southern-European countries, where niche pork husbandry (apart from the well-known free-range Iberian pig, which is not raised by default under organic standards) is not so well developed.

Quality perception of meat has been largely based on intrinsic cues like the colour of the meat, the visible fat and the cut. On the other hand, only a few extrinsic cues have been easily available because fresh meat is a largely unbranded product. Some of these 'adjectives' or credence attributes are animal welfare, product safety, health claims and environment (D'Souza, Cleary, \& Hewitt, 2017). Credence attributes play an important role in consumer choice, with these differing across countries. For example, the relative importance of production characteristics is bigger in Germany than in Poland, and they are related mostly to health and safety aspects, rather than to animal welfare (except for sow mobility claim in Germany) or environmental impact (Grunert, Sonntag, Glanz-Chanos, \& Forum, 2018).

Consumers' food-related lifestyles may affect purchasing cues of meat. Convenience-oriented consumers dislike food shopping, display less enjoyment in meal preparation, have fewer cooking skills, are accustomed to eating alone, and breaking down meals, whereas consumers that produce (or prosumers) receive utility in cooking (Casini et al., 2019). These consumer segments expressed differences in WTP for saving time in cooking, but little research is carried out to assess the effects of consumer culinary skills on purchasing cues of niche pork

\footnotetext{
* Corresponding author.

E-mail address: jalvarez@ca.udl.cat (J. Álvarez-Rodríguez).
} 
meat in Southern-European areas. This study aimed to evaluate the impact of culinary skills on their niche pork meat attitudes and purchasing cues in two country regions of North-Eastern Spain (Catalonia and Aragon) and the Northern region in Portugal (North). It was hypothesized that consumers' culinary skills would shift their attitudes and purchase WTP for niche pork in these contrasting cross-country situations.

\section{Material and methods}

\subsection{Research design and recruitment}

Survey data were collected through an on-line questionnaire with consumers in two country regions of North-Eastern Spain (Catalonia and Aragon) and the Northern region in Portugal (North) during April-May 2018. The questionnaire was developed in three languages: Spanish, Portuguese and Catalan in order to meet a wide variety of demographic profiles in the sample, and Whatsapp distributed as well as e-mail linked through snowball sampling. Total sample size amounted to 987 respondents. A minimum level of product experience is needed to ensure that effects of involvement are accurately measured (Verbeke \& Vackier, 2004). Hence, it can reasonably be assumed that a person with very little experience towards fresh meat is also very little involved. To exclude this potential bias, all respondents claiming to neither eat fresh or processed pork meat nor were responsible for meat purchasing within their household (13 out 987, 1.3\%) were removed from the initial sample, yielding a valid sample for the subsequent analyses of 974 respondents (Catalonia, $n=442$; Aragon and some other respondents from the rest of Northern Spanish area, $n=342$; and Northern Portugal, $n=190$ ), all of whom frequently consumed pork.

\subsection{Questionnaire}

The food-related lifestyle model (Grunert, 2006) was used as a conceptual framework in this study, as it has been considered as the intermediate level of a hierarchical cognitive system, and it distinguishes five elements: ways of shopping, cooking methods, consumption situations, quality aspects, and purchase motives. As involvement with the product category is likely to correlate with consumer experience (Sørensen, Grunert, \& Nielsen, 1996), this study dealt with this state of mind that motivates consumers to identify with product offerings, their consumption patterns and consumption behavior.

Each respondent was asked questions regarding consumer purchasing habits (15 questions, dichotomic true/false statements) (Table 1) to collect information about cooking methods and consumption situation (Hoek, Luning, Stafleu, \& De Graaf, 2004), and ways of shopping for pork (enjoyment of shopping, attitudes to advertising, importance of label information, importance of price, preference for specialty shops versus supermarkets and shopping list) (Bernués, Ripoll, \& Panea, 2012). These previous questions were used to segment the consumers according to their culinary skills. Certain socio-demographic characteristics, such as age of respondent, place of residence, household characteristics, education level, and gender, as well as frequency of meat consumption were also collected (Table 2). Additional questions concerned consumer involvement with pork (7 questions, on a 7-point scale, with 1 indicating totally disagree and 7 indicating totally agreement) (Table 3) (Borgogno, Favotto, Corazzin, Cardello, \& Piasentier, 2015).

The level of importance that consumers ascribe to different product cues that influence purchasing motives was assessed using a 5-point Likert scale, in which $1=$ none or very little importance, $2=$ little importance, 3 = average importance $4=$ quite a lot of importance and $5=$ great importance. The specific cues ( 20 questions) were selected from the literature, considering both intrinsic and extrinsic cues (Chamorro, Miranda, Rubio, \& Valero, 2012; Sepúlveda, Maza, \& Mantecón, 2008). Appearance (colour, drip loss) and fat content expectations were the intrinsic traits that were chosen, all of which are directly related to product appearance. The importance of other label factors that affect the purchasing cues were also ranked (label information, safety, traceability, known seller, quality certification, type of packaging, cooking ease, known brand, nutritional value, product, breed, price, type of cut, best before date, place of origin, slaughter method, slaughter date, cut weight).

The ranking of facts (as having visited a pig farm earlier) and beliefs (credence attributes such as animal welfare, animal husbandry, quality certification, breed/origin and certain health claims) related with the production process was assessed with 7 discrete response questions (yes/no/do not know), as follows: (i) Did you ever visit a pig farm? (ii) Do you think that pork contains hormone residues? (iii) Do you think that pork contains antibiotics residues? (iv) Do you think that pork contains a high level of fat? (v) Do you think that pork contains a high level of cholesterol? (vi) Do you think that pig husbandry guarantees animal welfare? (vii) Do you think that pig husbandry impairs the environment? (Table 4).

Choice-based pairwise tasks with graphical product simulations were found to be particularly suitable to measure preferences for

Table 1

Consumer segmentation based on food-related lifestyles.

\begin{tabular}{|c|c|c|c|}
\hline & Cluster 1 'uninvolved' (\%) & Cluster 2 'innovative cook lovers’ (\%) & Pearson $P$-value \\
\hline $\mathrm{n}$ & 462 & 512 & - \\
\hline \multicolumn{4}{|l|}{ Cooking methods } \\
\hline I like cooking & 48.5 & 94.1 & $<0.001$ \\
\hline Traditional recipes are best & 78.8 & 71.3 & 0.008 \\
\hline I spend a lot of time cooking & 10.4 & 32.0 & $<0.001$ \\
\hline I like changes in my meals & 28.8 & 92.8 & $<0.001$ \\
\hline Meal planning is important for family nutrition & 88.3 & 93.4 & 0.006 \\
\hline \multicolumn{4}{|l|}{ Consumption situation } \\
\hline I normally eat out on working days & 42.4 & 21.3 & $<0.001$ \\
\hline I like going to restaurants with friends and family & 87.2 & 87.3 & 0.97 \\
\hline I only eat pork meat at restaurants & 13.2 & 15.4 & 0.32 \\
\hline \multicolumn{4}{|l|}{ Ways of shopping } \\
\hline Do you enjoy shopping for food? & 70.8 & 80.7 & $<0.001$ \\
\hline Do you pay attention to advertisements? & 47.2 & 54.3 & 0.03 \\
\hline Is food label information important for you? & 87.2 & 95.5 & $<0.001$ \\
\hline Is price of pork important for you? & 61.3 & 87.5 & $<0.001$ \\
\hline Do you prefer specialist shops/butchers rather than supermarkets to buy pork? & 72.9 & 68.4 & 0.12 \\
\hline Do you follow a shopping list? & 67.5 & 71.9 & 0.14 \\
\hline Do you think that is it better to purchase pork on retail desk rather than packaged? & 74.7 & 72.3 & 0.40 \\
\hline
\end{tabular}


Table 2

Socio-demographics according to the food-related lifestyle clustering.

\begin{tabular}{|c|c|c|c|c|}
\hline & & $\begin{array}{l}\text { Cluster } 1 \text { 'uninvolved' } \\
(\%)\end{array}$ & $\begin{array}{l}\text { Cluster } 2 \text { 'innovative cook } \\
\text { lovers' (\%) }\end{array}$ & Pearson P-value \\
\hline $\mathrm{n}$ & & 462 & 512 & - \\
\hline \multirow[t]{3}{*}{ Geographical area } & Spain-Catalonia & 47.4 & 43.6 & 0.28 \\
\hline & Spain-Aragon & 35.1 & 35.2 & \\
\hline & Portugal-North & 17.5 & 21.3 & \\
\hline Gender & Female & 55.2 & 60.9 & 0.07 \\
\hline \multirow[t]{3}{*}{ Age } & $25-39$ years & 37.5 & 41.0 & 0.25 \\
\hline & 40-55 years & 40.3 & 36.9 & 0.28 \\
\hline & $>55$ years & 14.5 & 13.5 & 0.64 \\
\hline \multirow[t]{2}{*}{ Household characteristics } & Singles & 12.1 & 10.4 & 0.71 \\
\hline & No children & 56.9 & 54.1 & 0.38 \\
\hline Education & Higher & 81.4 & 77.3 & 0.12 \\
\hline \multirow[t]{3}{*}{ Living environment } & Urban ( $>10,000$ inhabitants) & 60.8 & 65.2 & 0.34 \\
\hline & $\begin{array}{l}\text { Medium sized (2000-10,000 } \\
\text { inhabitants) }\end{array}$ & 21.4 & 19.7 & \\
\hline & Rural (<2000 inhabitants) & 17.8 & 15.0 & \\
\hline \multirow[t]{3}{*}{ Most purchased pork joint } & Boneless loin & 54.6 & 55.1 & 0.80 \\
\hline & Spareribs and rib chops & 15.8 & 14.8 & \\
\hline & Tenderloin and lean mince & 19.5 & 21.3 & \\
\hline \multirow[t]{3}{*}{ Frequency of fresh pork consumption } & 3-4 times/week & 17.3 & 16.6 & 0.77 \\
\hline & 1-2 times/week & 50.4 & 53.3 & \\
\hline & Less than once/week & 29.4 & 27.2 & \\
\hline \multirow{3}{*}{$\begin{array}{l}\text { Frequency of processed pork consumption (dry-cured pork } \\
\text { products and cooked ham) }\end{array}$} & 3-4 times/week & 34.9 & 33.6 & 0.44 \\
\hline & 1-2 times/week & 31.8 & 31.8 & \\
\hline & Less than once/week & 17.1 & 20.9 & \\
\hline
\end{tabular}

Table 3

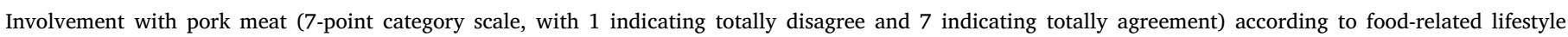
clustering.

\begin{tabular}{|c|c|c|c|c|}
\hline & Cluster 1 'uninvolved' & Cluster 2 'innovative cook lovers' & Pooled standard error & Wilcoxon P-value \\
\hline \multicolumn{5}{|l|}{ Product importance } \\
\hline I do not care at all about the pork meat & 1.95 & 1.89 & 0.08 & 0.11 \\
\hline Pork is very important to my diet & 3.65 & 3.80 & 0.07 & 0.14 \\
\hline \multicolumn{5}{|l|}{ Hedonic value } \\
\hline I can say that I actually do not like to eat pork & 2.27 & 2.29 & 0.08 & 0.88 \\
\hline I enjoy a meal with pork more than a meal without pork & 3.34 & 3.33 & 0.07 & 0.80 \\
\hline \multicolumn{5}{|l|}{ Symbolic value } \\
\hline You can tell a lot about a person based on his/her choice of meat & 3.36 & 3.51 & 0.08 & 0.23 \\
\hline \multicolumn{5}{|l|}{ Risk importance } \\
\hline I would find a bad choice of meat terrible & 3.72 & 3.97 & 0.08 & 0.03 \\
\hline \multicolumn{5}{|l|}{ Risk probability } \\
\hline I never know if I make the right choice of pork & 3.29 & 3.23 & 0.08 & 0.50 \\
\hline
\end{tabular}

products with strong visual components, such as visual fat content, which cannot accurately be represented by verbal scale items (Mueller, Lockshin, \& Louviere, 2010). The consumers were asked to choice their purchase intention between two types of boneless two loins with contrasting fat contents (including subcutaneous and intermuscular fat) (Fig. 1).

In the contingent valuation approach, consumers state their WTP to procure the good. The use of this method is especially suitable to capture consumers' WTP for a specific product or characteristic in the absence of actual market data. As the methodological approach to calculate the respondents' WTP for specific meat is conditioned to the question format (Angulo, Gil, \& Tamburo, 2005), the respondents were requested to note the maximum amount of money they were willing to pay for marbled boneless pork loin (Fig. 1, left). The consumers had seven choices, with a price bid from 5 to $8 € / \mathrm{kg}$ at $0.5 € / \mathrm{kg}$ intervals in Spain, and a mark on $5.5 € / \mathrm{kg}$, that is the reference mean price for retail sliced boneless pork loin (MAPA, 2018b), and from 3.0 to $6 € / \mathrm{kg}$ at $0.5 € / \mathrm{kg}$ intervals in Portugal, and a mark on $3.5 € / \mathrm{kg}$, that is the mean price for retail sliced boneless pork loin in major supermarkets of the northern area (no reference Portuguese prices were available).

Table 4

Credence attributes concerns according to the food-related lifestyle clustering.

\begin{tabular}{|c|c|c|c|}
\hline & Cluster 1 'uninvolved'(\%) & Cluster 2 'innovative cook lovers’ (\%) & Pearson P-value \\
\hline $\mathrm{N}$ & 462 & 512 & - \\
\hline I have already visited a pig farm & 77.7 & 76.2 & 0.83 \\
\hline I think that pig husbandry guarantees animal welfare & 57.1 & 60.7 & 0.43 \\
\hline I think that pig husbandry impairs the environment & 52.8 & 51.6 & 0.62 \\
\hline I think that pork contains hormone residues & 38.7 & 41.6 & 0.64 \\
\hline I think that pork contains antibiotics residues & 48.5 & 47.5 & 0.94 \\
\hline I think that pork contains a high level of fat & 40.5 & 40.4 & 0.90 \\
\hline I think that pork contains a high level of cholesterol & 32.0 & 27.3 & 0.24 \\
\hline
\end{tabular}



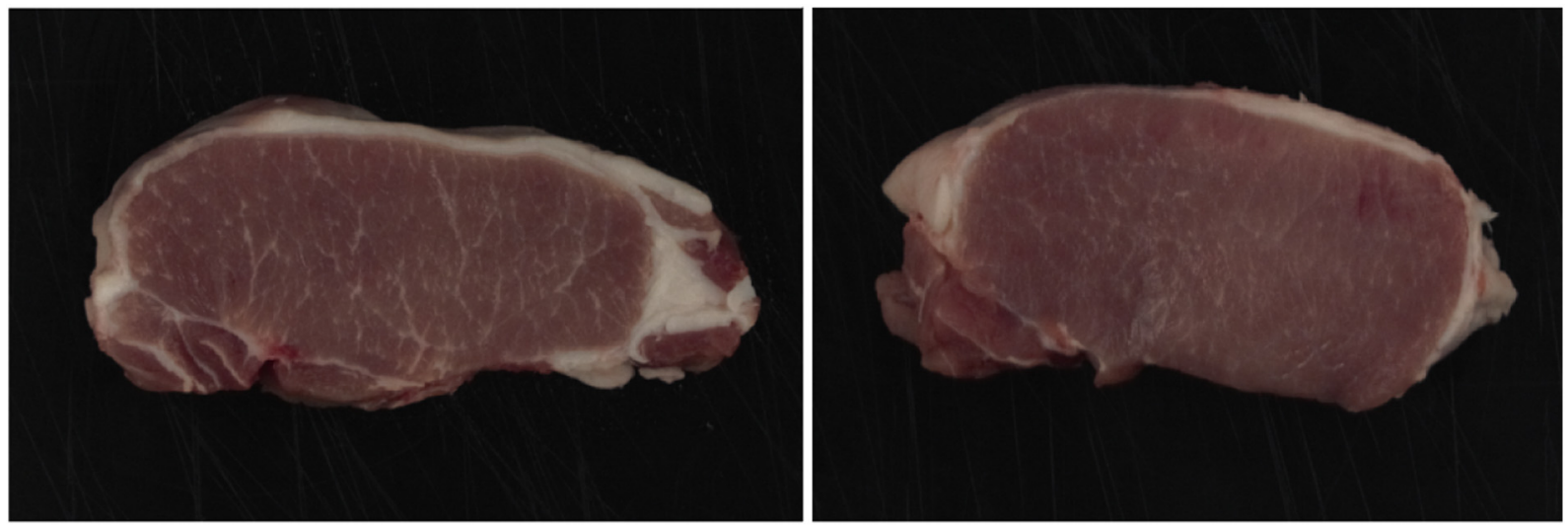

Fig. 1. Boneless marbled loin (3.4\% of intramuscular fat content) (left) and lean pork (1.7\% of intramuscular fat content) (right).
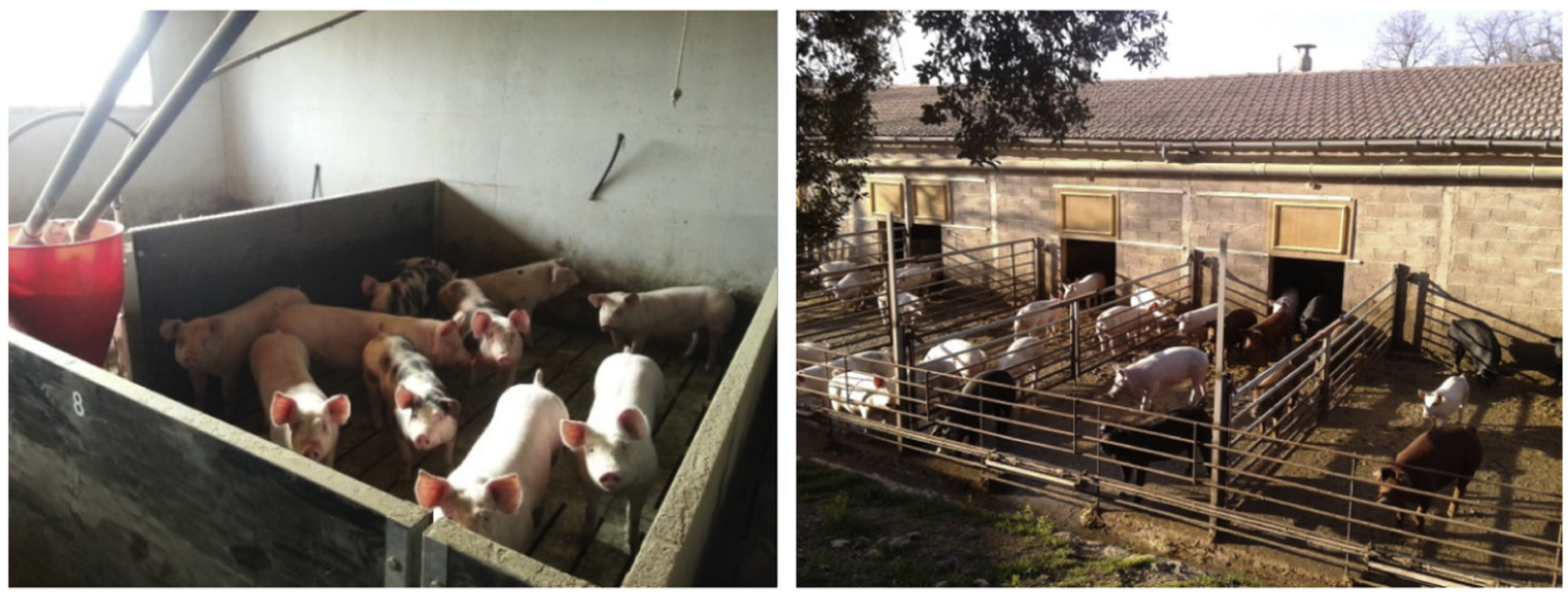

Fig. 2. Pigs housed indoors with standard space allowance and concrete-slatted pens (left) and pigs housed with high space allowance and outdoor run (right).

Subsequently, they were asked for their WTP with the same procedure for pork coming from different finishing pig farm facilities (without any additional indication of quality label) in the Iberian Peninsula framework (Fig. 2) as well as for organic pork, by showing them the declaration of the official European Union organic standards logo.

\subsection{Statistical analyses}

Data analyses were carried out with JMP (13.0.01 version; SAS Institute Inc., Cary, NC). Consumer segmentation of pork meat based on culinary skills (food-related lifestyles dimensions) was accomplished through hierarchical clustering. Optimal number of clusters was identified at highest CCC (Cubic Clustering Criterion). Differences between clusters concerning socio-demographic variables and importance of extrinsic attributes were assessed with contingency tables with Pearson tests. Non-parametric Wilcoxon tests with pair-wise comparisons were conducted to cross the consumer clusters based on food-related lifestyles with their involvement scores, purchasing drivers and WTP for different pork loins. Partition tree predictive modelling was used as a data mining technique to predict willingness to pay for different picture scenarios (marbled loin, pigs housed indoors, pigs with outdoor run and organic logo) as a function of potential predictor variables (socio-demographics, lifestyles, credence attributes) using recursive partitioning. The partition algorithm searched all possible splits of predictors to best predict the response (WTP). These splits (or partitions) of the data were done recursively to form a tree of decision rules. The variables were selected according to G2 (likelihood-ratio chi-square) test of association (lower values indicate a better fit) and $\log$ worth $(-\log (p$-value $))$ value. The Logworth values are the logs of adjusted $p$-values for the chi-square test of independence. Minimum size split in partition trees was set at $3 \%$ of the total sample size.

\section{Results and discussion}

\subsection{Consumers that do not purchase meat (but indeed consumed meat)}

Consumers that did not purchase meat nor did not consume pork were excluded from the analysis. However, a small proportion of consumers $(n=50,5.1 \%)$ that did not purchase meat were indeed pork consumers, and were included in the study. This consumer type was mainly located in Catalonia (60\%, compared to $18 \%$ in Aragon and $22 \%$ in Northern Portugal), they were gender-balanced (56\% females), young adults (54\% ranging $25-39$ years), without children (60\%), with higher education and living in an urban environment ( $>10,000$ inhabitants) (64\%). Thirty-six percent out of this category did not consume fresh pork, while only $4 \%$ did not consume any processed pork products.

\subsection{Socio-demographics and involvement with pork in consumer clusters} based on culinary skills

Consumer segmentation based on culinary skills is shown in Table 1. Two optimal clusters were identified based on food-related habits. Cluster 1 was named as 'uninvolved' because its components liked cooking to a lesser extent $(P<.001)$, normally ate out on working days $(\mathrm{P}<.001)$, considered traditional recipes best $(P=.008)$, spent less time cooking $(P<.001)$, did not like changes in their meals $(\mathrm{P}<.001)$, considered less important meal planning for family 
nutrition $(\mathrm{P}<.001)$, enjoyed to a lesser extent shopping for food $(\mathrm{P}<.001)$, payed less attention to advertisements $(P=.03)$ and food label information $(\mathrm{P}<.001)$ and considered price of pork less important $(\mathrm{P}<.001)$ than Cluster 2 , that was named as 'innovative cook lovers', that liked cooking and making changes in their meals. Interestingly, the two clusters did not differ widely in their social consumption situation and ways of shopping, as the proportion of consumers enjoying eating out with family and friends, following a shopping list, preferring specialty shops or butchers rather than supermarkets, or over the counter purchases rather than packaged did not differ.

In this study, pork purchased over the counter was preferred by consumers, although purchasing behaviour in Spain is evolving to supermarkets/hypermarkets in all meats, but especially in pork (55\% of total market share) (MAPAMA, 2018a). The 'uninvolved' group was less concerned about advertisements, label information or price of pork than 'innovative cook lovers'. In another Spanish survey, the consumer segment that rated less importantly price and offers preferred purchasing organic food in specialist shops rather than in supermarkets (MAPAMA, 2017). In the present study, the difference between consumer segments regarding purchasing place did not reach statistical significance.

The socio-demographic characteristics according to the food-related lifestyle clustering are shown in Table 2 . There was no significant difference across clusters $(P>.05)$ for country regions, ages, household characteristics, education, living environment and pork consumption habits. Cluster 1 ('uninvolved') tended to include less women compared to cluster 2 ('innovative cook lovers') $(P=.07)$.

Spain and Aragon account for $9.1 \%$ and $2.0 \%$ out of total EU-28 population, respectively (Eurostat, 2018), and represent a comprehensive view of the South-European pork consumer profile. The three regions studied differ widely in pig farm density and/or human population density. For example, Catalonia (North-Eastern Spain) is a high populated region (235 inhabitants $/ \mathrm{km}^{2}$ ) with a very high presence of the swine sector $\left(237 \mathrm{pigs} / \mathrm{km}^{2}\right.$ ), whereas Aragon (North-Eastern Spanish region attached to Catalonia) is a very low populated region (27 inhabitants $/ \mathrm{km}^{2}$ ) but has a rather high presence of the swine sector (148 pigs $/ \mathrm{km}^{2}$ ). On the opposite side of the Iberian Peninsula, the Northern region of Portugal is a moderately populated region (173 inhabitants $/ \mathrm{km}^{2}$ ) but has a very low presence of the swine sector (only $3 \mathrm{pigs} / \mathrm{km}^{2}$ ) (INE, 2018a; INE, 2018b). In looking at the meat consumption behaviour, pork is the most consumed meat in Spain (49.1 kg/capita) and Portugal (43.7 kg/capita) (MAPA, 2018a; INE, 2018a), that have greater average pork consumption per capita than the EU-28 shares (40.7 kg/capita) (Eurostat, 2018).

It is noteworthy that socio-demographics did not differ across consumers, with only a tendency towards more women in the 'innovative cook lovers' segment. Therefore, the food-related lifestyles were similar across countries (Spain vs. Portugal) and regions within Spain (Catalonia vs. Aragon). The density of pig production may affect the cultural perception of meat, as it has been reported that, in north European countries, consumers living in areas with higher levels of pig production consumed fresh pork more frequently than those in lower density areas (Verbeke, Pérez-Cueto, de Barcellos, Krystallis, \& Grunert, 2010). However, this was not evidenced in this south European area, which could be related to low rating of meat as healthy.

In the present study, at least half of the consumers ate pork once or twice a week and only approximately $17 \%$ consumed fresh pork 3-4 times per week. However, the proportion of consumers with frequent consumption (3-4 times per week) of processed pork products (e.g. drycured ham) doubled (34\%) the frequency of consumption of fresh pork. This is in agreement with a previous European survey, where consumers chose fresh pork for special occasions or weekends, and more processed and convenient products for every day occasions, when they consume pork alone or when socializing (Verbeke et al., 2010).

The principal factors underlying consumer involvement according to food-related lifestyle clustering are shown in Table 3. The questions responses are classed according to the 5 sub-dimensions of consumer involvement developed by Laurent and Kapferer (1985). Risk importance was the main scored sub-dimension of pork, and it was also lower in 'uninvolved' than in 'innovative cook lovers' $(P<.05)$. However, product importance, hedonic value, symbolic value and risk of probability did not differ between clusters $(P>.10)$.

Convenience orientation, that is defined as savings of time, physical energy, or mental energy that occurs during one or more of the phases of the home food production (deciding what to eat, purchasing, preparation, consumption and cleaning up), is also affected by other factors, notably food-related motives, like involvement with food (Grunert, 2006). In this study, consumer involvement with pork did not differ between consumer segments, except risk importance dimension, in which 'innovative cook lovers' would regret more a bad choice of meat compared to 'uninvolved' consumers. Consumers' satisfaction with taste (hedonistic value) is the main factor affecting overall satisfaction with pork meat and derived products (Resano et al., 2011), but in this study, the hedonistic value dimension was not different between both consumer segments.

The bulk of food products are still mainly targeted more at the uninvolved than at the food-loving consumer segments. Food-loving consumer segments typically like to retain degrees of freedom in their meal preparation (Grunert, 2006). This could explain that the proportion of 'innovative cook lovers' who liked changes in their meals was three times higher than the proportion of 'uninvolved' consumers expressing this attitude.

\subsection{Purchasing drivers according to culinary skills clustering}

The purchasing drivers according to culinary skills clustering are ranked in Fig. 3. Regardless of lifestyle group, 'best before date', 'safety' and 'appeal (colour, drip loss)' were the most important criteria for purchase decision; all of them were scored over 4 on the importance scale. The next most important factors for the 'innovative cook lovers'

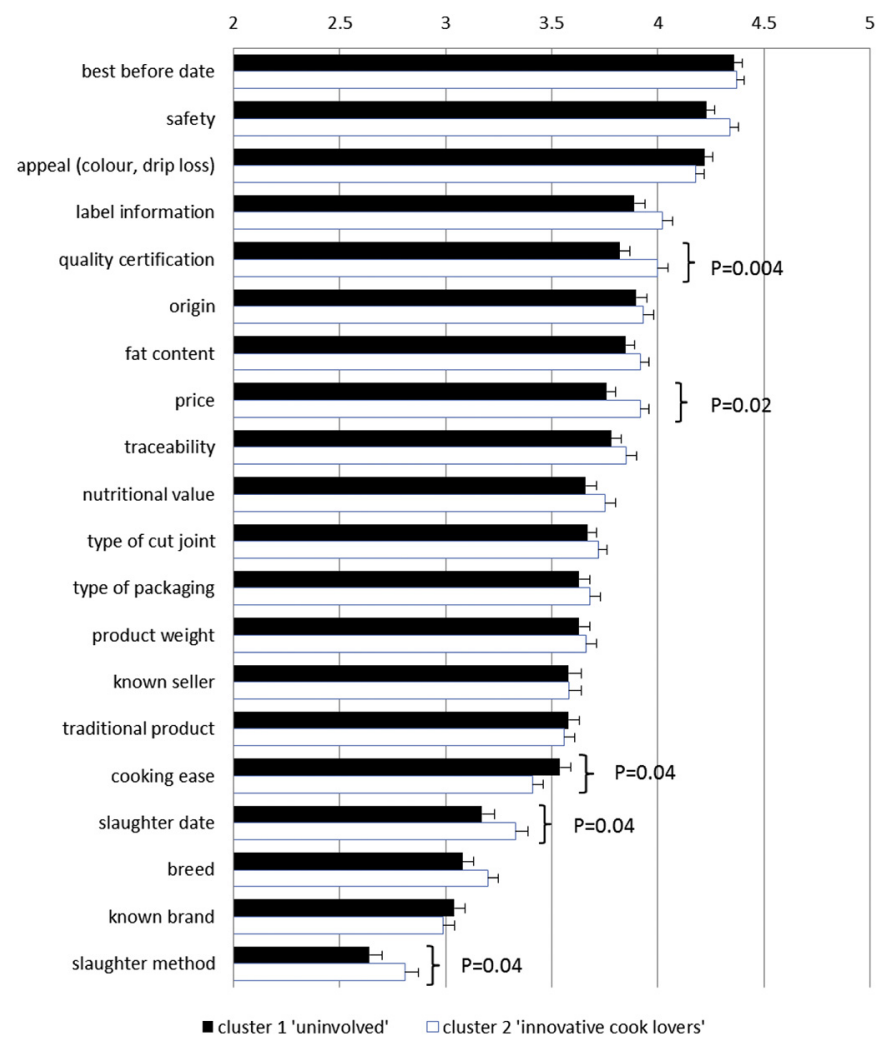

Fig. 3. Purchasing drivers ranked according to food-related lifestyle clustering. 
cluster were 'label information' and 'quality certification', that tended $(P=.09)$ or were indeed rated higher $(P=.004)$, respectively, than 'uninvolved' consumers. By default, consumers may believe that conventional or unlabeled meat products contain perceived risks surrounding pork production and consumption, which could potentially lead to the devaluation of these products in a market where they become the 'cheap' or 'generic' products (Abrams et al., 2010). The labelling issue is strengthening in importance, as some other label information data have been proposed in Germany to promote organic animal products produced with local feed, such as feed imports declaration (Wägeli, Janssen, \& Hamm, 2016). In fact, origin of pork was scored similarly to label information and quality certification. Thus, consumer cues related to both origin and brand are being used when choosing meat, as suggested by Banovic, Grunert, Barreira, and Fontes (2010). However, in this study, known brand was at the bottom of the purchasing drivers of pork, although quality certification had been one of the most scored.

In intermediate position ( 3 to 4 score rank), consumers rated (in this order): 'origin', 'fat content', 'price', 'traceability', 'nutritional value', 'type of cut joint', 'type of packaging', 'product weight', 'known seller', 'product', 'cooking ease', 'slaughter date' and 'breed'. Both extrinsic (safety) and intrinsic (appeal) cues were important, regardless of consumer cluster. However, the fat content of meat fell to a secondary position as purchasing driver, at the same level to price. Ngapo, Martin, \& Dransfield (2007a) observed that preferences differed considerably between individuals, between groups and between countries when comparing equivalent subsets of consumers taken from each country. According to them, most choices were based on two appearance characteristics, colour (dark or light red with no drip) and fat content (low), although some differences arose among countries (Spain and Portugal not included there). In the present study, fat content was scored similarly as a purchasing cue by both consumer clusters. In addition, respondents preferred purchasing the marbled over lean loin sample, regardless of cluster ( $68.4 \%$ vs. $67.2 \%$, in 'uninvolved' compared to 'innovative cook lovers', $P=.69$ ). This finding is in agreement with Font-i-Furnols, Tous, Esteve-Garcia, and Gispert (2012), who found that nearly half of the consumers preferred marbled compared to lean loin slices, although according to their eating acceptability scores, all their consumers preferred loins with higher IMF levels. Accordingly, these authors suggested that a minimum intramuscular fat content ranging between $2.2 \%$ and $3.4 \%$ would be desired to ensure a good taste.

The increasing concern about health and safety issues may fuel an increased use of extrinsic cues not currently available in label information. In a German sample ranking pork extrinsic cues (as measured by both knowledge and importance), Grunert, Skytte, Esbjerg, Poulsen, and Hviid (2002) found that the top five were mainly related to healthiness and process characteristics (no pesticide residues, no genetically modified feed, fat percentage, animal friendly farm, and animal friendly transport) and not related with sensory quality. In beef, the most relevant cues or attributes perceived to signal that meat was not safe were expired 'use by' dates, foreign origin, the level of processing e.g. minced, offal or otherwise processed, and price (too cheap) (Verbeke et al., 2010).

Among intermediate ranked drivers, the 'price' importance and 'slaughter date' were greater $(P<.05)$ whereas 'cooking ease' was less valued $(P=.04)$ by 'innovative cook lovers' than by 'uninvolved' consumers, as verified by Bernués et al. (2012) in a consumer survey of lamb meat.

In a cross-sectional web-based survey in Belgium, Denmark, Germany, Greece, and Poland, Resano et al. (2011) concluded that tasty pork, easy to use and consume, with an adequate promotion of its healthfulness, and with a good price/quality relationship appears to be the key to satisfy pork consumers, regardless of country. However, in this study, the 'innovative cook lovers' consumer segment ranked the price of pork more importantly than 'uninvolved' consumers, suggesting that within each country, price is a key cue for most exigent consumers. This is in line with Grunert (2006), who identified two consumers segments based on ways of shopping: one segment ( $41 \%$ of consumers) is price conscious, with price being the major factor influencing their choice. The other segment (61\% of consumers) was quality conscious, and used the price cue as a quality cue and not as a cost cue. In fact, $>80 \%$ of the consumers thought that pork was not expensive (Ngapo, Martin, \& Dransfield, 2007b).

The least rated criteria driving purchase intention were 'known brand' and 'slaughter method', although the latter was scored greater by 'innovative cook lovers' than by 'uninvolved' $(P=.04)$. According to a survey of the European Commission (2015a), the consumers who purchase meat are generally satisfied with the information available on meat and meat products ( $80 \%$ of respondents). The absence of apparent demand for additional information does not, however, preclude the possibility that consumers expect certain standards to be adhered to. The information regarding pre-slaughter stunning of animals was not spontaneously mentioned as a criterion for buying meat and only when directly asked, $72 \%$ of respondents indicated interest in receiving information on it. The afore-mentioned survey thereby concluded that for most consumers information on pre-slaughter stunning is not an important issue unless brought to their attention. However, this may gain importance for a certain proportion of motivated consumers, although it is unclear how consumers would actually act on this information if it was available.

\subsection{Credence attributes views according to culinary skills clustering}

Credence attributes concerns according to culinary skills clustering are shown in Table 4. Any of these quality cues differed between cluster groups $(P>.05)$. Most of the respondents had already visited a pig farm $(77 \%)$, and more than half $(59 \%)$ considered that pig husbandry guarantees animal welfare. However, more than half $(52 \%)$ claimed that pig husbandry impairs the environment. From a health view, around $40 \%$ of respondents considered that pork contains hormone residues while nearly half of them (48\%) claimed that pork contains antibiotics residues. In addition, approximately $40 \%$ of the sample considered that pork contains a high level of fat but only $30 \%$ claimed that pork had a high level of cholesterol.

The present study revealed that some credence attributes were irrespective of consumer segment. More than half of consumers considered that animal husbandry guaranteed their welfare, but also more than half of respondents expressed a great concern about the environmental burden when raising pigs. In fact, 'housing and floor type' and 'efforts to protect soil, air and water at the farm' had been the items that had the strongest influence on citizens' evaluation of pig production systems (Verbeke et al., 2010). These authors found that people who care about animal welfare and small-scale pig production consumed less pork and/or in a more selective way. For example, the vegetarians have the same level of food-related motivation as other consumer groups, but a different motivational profile and distinctive, taste- and animal-welfare related reasons to justify their abstinence from eating meat (de Boer, Schösler, \& Aiking, 2017). It should be noted that approximately $28 \%$ of the consumers included in this study consumed fresh pork less than once a week, and this proportion was similar in both consumer segments, so it may be expected that the yearly fresh pork consumption per capita will slowly decline, at least, until year 2025 (European Commission, 2015b).

\subsection{Willingness to pay for different attributes of boneless pork loin}

The cluster group based on culinary skills did not affect the WTP for marbled loin ( 5.63 vs. $5.55 \pm 0.05 € / \mathrm{kg}$, by 'uninvolved' and 'innovative cook lovers', respectively, $P=.25$ ), loin from indoor husbandry (5.35 vs. $5.30 \pm 0.04 € / \mathrm{kg}$, respectively, $P=.47$ ), loin from outdoor run husbandry (5.93 vs. $5.93 \pm 0.05 € / \mathrm{kg}$, respectively, $P=.87$ ), or organic loin (6.17 vs. $6.14 \pm 0.05 € / \mathrm{kg}$, respectively, 


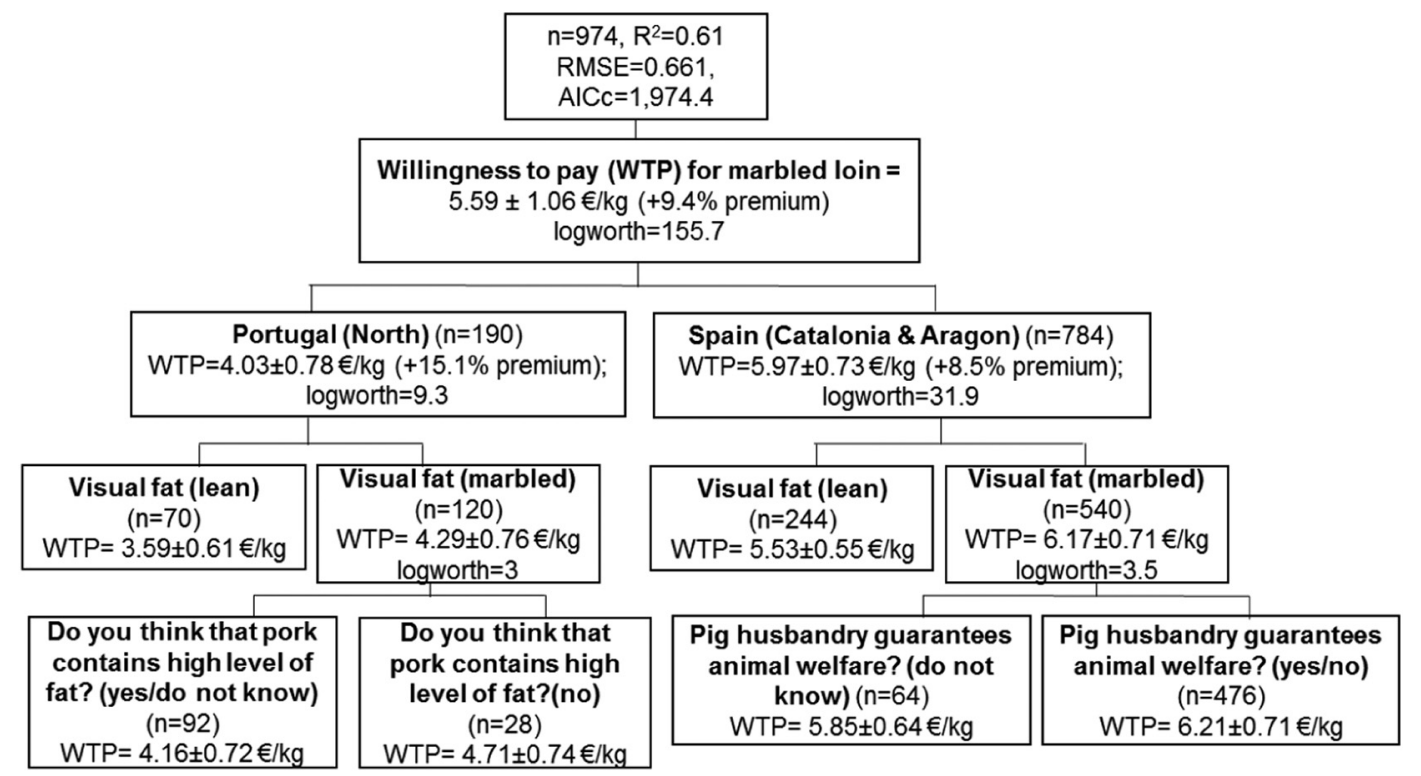

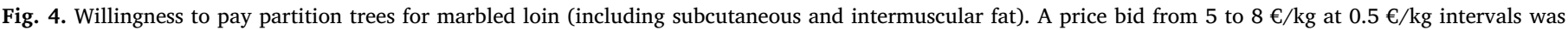

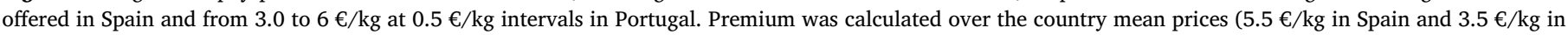
Portugal).

$P=.72)$.

The partition tree WTP for marbled loin (Fig. 4) showed that, in each country, the best predictor was visual fat content preference. The consumers selecting to purchase marbled loin over lean loin would have paid more for it $(+11.6 \%$ and $+19.5 \%$ in Spain and Portugal, respectively) (log-worth $>2$ ). It is noteworthy that no differences could be detected between the two Spanish regions studied regarding WTP for any pork loin alternative. In Spain, the consumers that do not issue an opinion about the welfare conditions of pigs would have paid less for marbled pork loin. However, in Portugal, the WTP of marbled pork was higher when the consumers do not think that pork contains high level of fat.

In this study, more than half of the consumers would prefer higher IMF content, and those who have chosen it would have paid more for marbled meat, regardless of country. Marketing strategies emphasizing the importance of marbling in eating quality would possibly help the consumers that reject high IMF levels to understand this intrinsic attribute of pork. This implies that the IMF content of pork loin may be increased (at least until 3.4\%) across the Spanish and Portuguese markets to satisfy (at least) the expectations of half of the consumers. High marbling is normally found in organic pork due to dietary conditions in the pigs, which lack in-feed synthetic amino acids and may include full oilseeds or mechanically oil extracted (Alvarez-Rodriguez, Villalba, Cubilo, Babot, \& Tor, 2016).

In Spain, the WTP for marbled pork varied according to their knowledge about pig welfare, while in Portugal the WTP for marbled pork depended on concern on its fat content. In general, the amount of visible marbling negatively affects the consumers' purchase intention most likely due to an unhealthy claim (Resurrección, 2003). However, it was shown that WTP for marbling is also affected by credence attributes as animal welfare knowledge. In this regard, it would appear that only a small proportion of consumers (at least in Australia) is willing to pay a premium for animal welfare, even though most would rate this as being very important (D'Souza et al., 2017). This could explain the unsteady response for higher WTP for marbled pork by both critical and non-critical consumers with regard to animal welfare.

The partition tree WTP for pork coming from indoor husbandry (Fig. 5) was mainly affected by consumers' age in Spain (log-worth $>$ 2 ), since young adults (25-39 years old) would have paid less than the rest of age groups $(-2.3 \%)$, whereas in Portugal the WTP differed between environmental concern views about pig production, as those unaware of that would have paid more than those doubtful or concerned about it (log-worth $>2$ ). The partition tree WTP for pork coming from farms having outdoor runs was best explained in Spain by concerns about antibiotics residues in pork (log-worth $>2$ ). The consumers considering that pork contained antibiotics residues would have paid more $(+3.7 \%)$ for pork coming from farms having an outdoor run than those not concerned. In Portugal, the WTP for pork from farms having an outdoor production was affected by concern about hormone residues in meat, as those thinking that pork may contain hormone residues (yes or doubtful answer) would have paid less $(-9.3 \%)$ than those not having this concern.

In Spain, elderly people are more likely to be satisfied with fresh pork and pork meat products (Resano et al., 2011), which could explain their higher WTP for standard pork raised in indoor facilities. In case of Portugal, the consumers avoiding penalties on the environmental hazards of pig production would have paid more for pork indoors, but this difference was not observed in Spain. In a Finnish study, the consumer environmental consciousness is yet unsure and the neutral stand is the most common attitude (Pohjolainen, Tapio, Vinnari, Jokinen, \& Räsänen, 2016), however, the reduction of meat production was identified by $25 \%$ of consumers as a solution for environmental burden. Perhaps, the lower swine density in this northern Portugal area does not impair so far the consumer view on commodity indoor pork.

The WTP for outdoor pork was cross-country affected by credence attributes (antibiotics residues concerns in Spain, and hormone residues in Portugal). However, the attitude towards process characteristics differed between countries, since in Spain the greatest WTP for outdoor pork was obtained by respondents concerned about presence of antibiotic residues in pork, while in Portugal it was expressed by respondents who did not think that pork may contain hormone residues, or, in other words, by consumers less concerned by public health hazards.

Finally, in Spain, the partition tree WTP for organic pork (Fig. 6) was also explained mainly by concern about antibiotics residues, but this difference was not detected in Portugal, where women would have paid more for organic pork than men $(+6.8 \%)$. In Spain, among the consumers that do not have an opinion or think that pork does not contain antibiotics residues, the subset of consumers with interest for level of pork fat would have paid more for pork loin $(+10.2 \%)$. 
a)

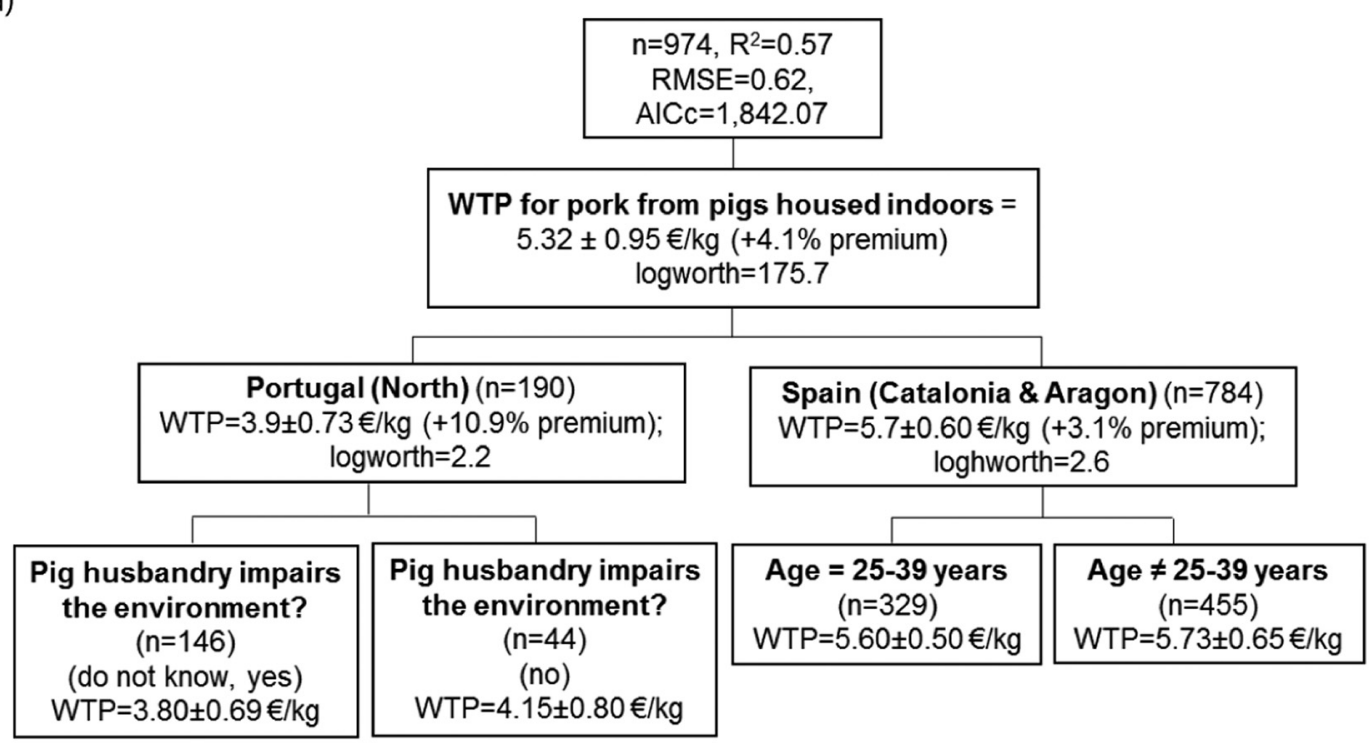

b)

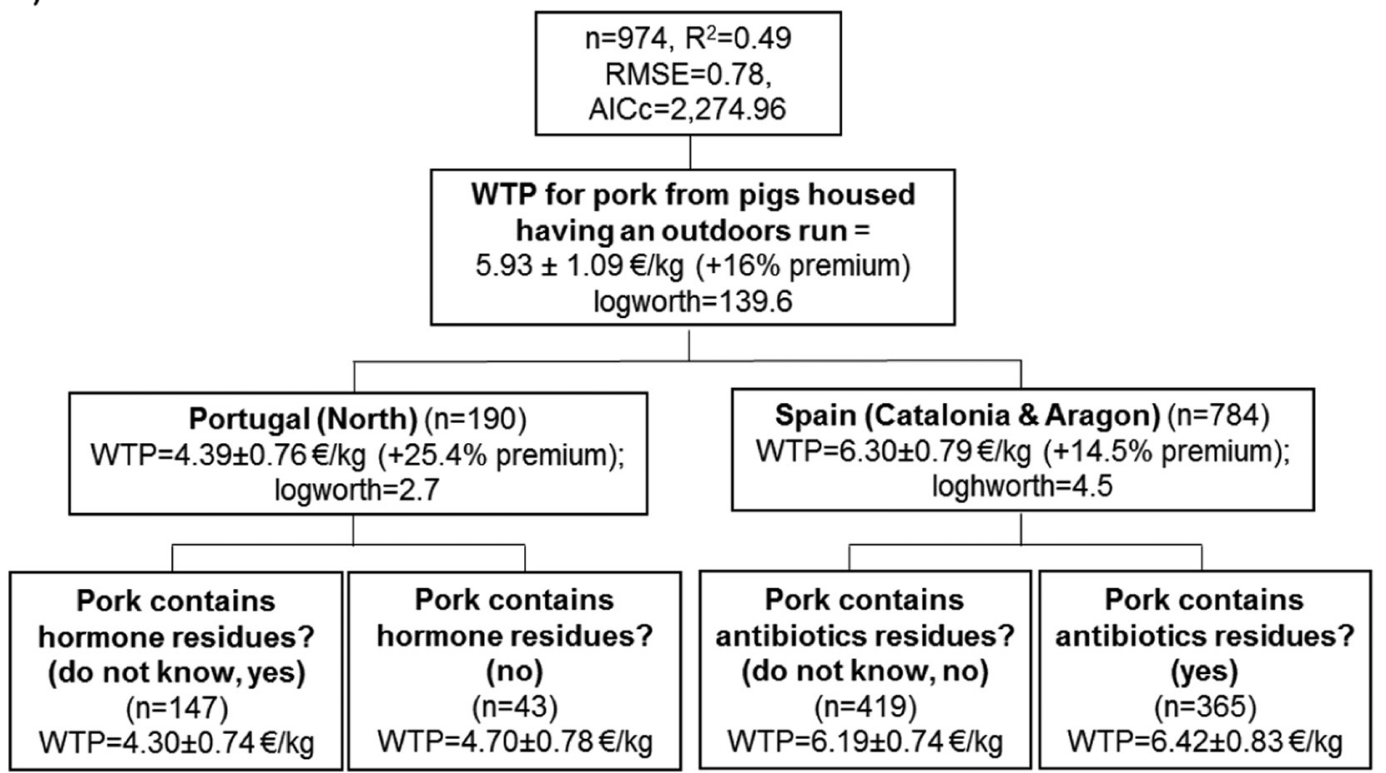

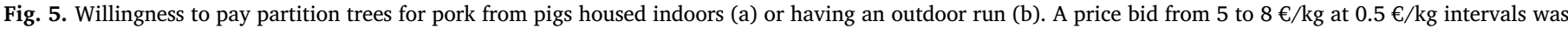

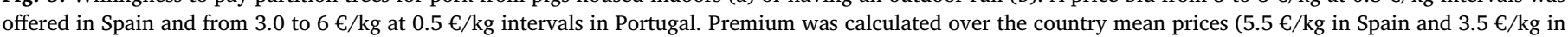
Portugal).

In Spain, similarly to outdoor pork response, the WTP for organic pork was higher when the consumers were concerned about antibiotic residues in pork, but this outcome was not seen in Portugal. In fact, the perception of product safety had been one of the main WTP determinants for certified beef by Spanish consumers (Angulo \& Gil, 2007). Perception of food safety risk is a psychological interpretation of product properties (Yeung \& Morris, 2001), that can affect negatively pork choice. Education may enhance the positive effect of trust in information provided by public authorities and weaken the negative effect of trust in information provided by mass media, which normally contributes to amplify the negative perception of food safety (Angulo \& Gil, 2007). It may be suggested that the greater pig density in Spain compared to Portugal, especially in the studied regions, is negatively affecting the public image of pork, when certain risks or hazards are shown in mass media.

An organically produced piece of meat was considered better not only in terms of its process characteristics, but also in terms of healthiness and sensory quality (Scholderer, Nielsen, Bredahl, ClaudiMagnussen, \& Lindahl, 2004). In this mentioned study, consumers believed that when they tasted organic or free-range pork they actually perceived the quality of the meat was higher, irrespective of which type of meat they actually eat. In the present study, the factors affecting WTP for outdoor and/or organic pork by Spanish respondents proves that some credence attributes (as no presence of antibiotic residues) are not being accurately addressed or described in commodity pork. In addition, in case of Portugal, the WTP for organic pork was higher in women than in men. This response does not seem cross-country steady, as in the USA it was the opposite (Vander Naald \& Cameron, 2011). Lagerkvist and Hess (2011) concluded from a meta-analysis that whether such a gender effect on WTP for farm animal welfare may exist, but was at least statistically severely confounded by related characteristics of the respondents that apply equally to men (for example, related with income or household children).

In a survey analyzing public perception of animal welfare in Spain 


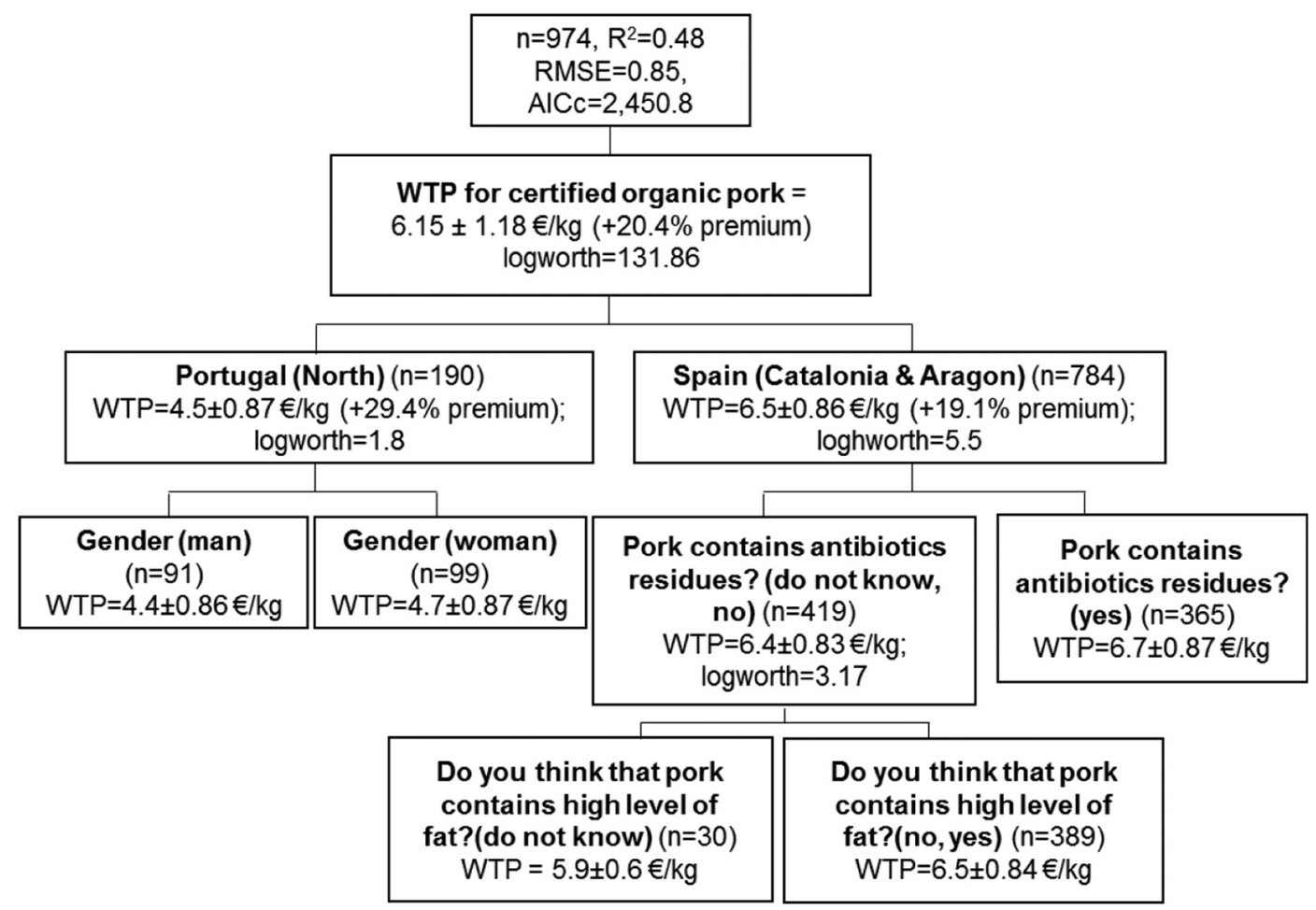

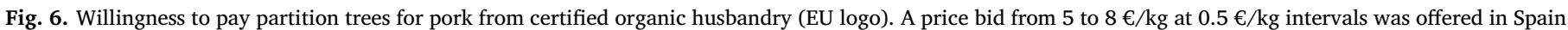
and from 3.0 to $6 € / \mathrm{kg}$ at $0.5 € / \mathrm{kg}$ intervals in Portugal. Premium was calculated over the country mean prices (5.5 €/kg in Spain and $3.5 € / \mathrm{kg}$ in Portugal).

(María, 2006), a high proportion of urban people agreed to pay more for animal products, if this greater price would guarantee a better welfare. In that study, there was a trend indicating a positive response in young women (university students). However, there was an inconsistency between the higher WTP and the actual consumption of welfare friendly products, which remained low. Accordingly, as citizens, people may hold views about various forms of meat production, but these may be only weakly reflected in their behaviour as consumers. For example, community attitudes can be critical with certain forms of meat production on animal welfare grounds, but consumers still buy the products of these systems, even though products with better animal welfare standards may also be available (Grunert, 2006; Ngapo et al., 2004; Verbeke et al., 2010). In France, for example, 39\% of households did not purchase any organic products, as the 'all-organic' basket costs a $62 \%$ premium over that of the 'all-conventional' basket. Across Europe, Switzerland has the highest per capita consumption of organic food, followed by Denmark and Sweden (FiBL, 2017).

In a recent study evaluating urban consumers' WTP for pork with certified labels in China, there were cross-regional differences in this variable depending on their economic development (Wang, Ge, \& Ma, 2018). Assuming that the gross domestic product (GDP) per capita is an approach measure for the economic activity, the current volume index of GDP per capita in purchasing power standards for Spain and Portugal is 92 and 77 (set at 100) (Eurostat, 2018). As familiarity with the type of tested product is the main factor accounting for WTP (Sanjuán et al., 2012), the WTP for niche pork (outdoor and/or organic) in these countries is expected to progress forward depending on their economic trend. In fact, in a survey from Catalonia, meat was the most important food type that the organic consumers were willing to increase its purchase (37\% out of organic consumers) (Gencat, 2015).

The overall mean WTP premium across countries was low for indoor pork image $(7.0 \%)$, but increased for marbled (11.8\%), outdoor pork (20.0\%) and organic logo stamp (24.3\%). However, the goodness of fit of the explanatory variables (based on $\mathrm{R}^{2}$-square and Root mean square error, RMSE) was negatively related with the observed WTP value (lower $\mathrm{R}^{2}$-square for higher WTP product). The overall scenario premiums were $8.9 \%$ lower in Spain than in Portugal. These shares are in agreement with the results from France and the Netherlands, where questionnaire responses suggested that almost half of consumers would pay $20 \%$ more for pork from pigs raised outdoors (Carpentier \& Latouche, 2005). However, some other references suggest that consumers would offer only $5 \%$ extra, with about one-fifth of consumers willing to pay $20 \%$ extra for organic pork (Dransfield et al., 2005). In a study carried out in Canada and Germany to evaluate the influence of consumer knowledge on environmentally sustainable choices, it was found that about $20 \%$ of consumers in both countries were ready to adopt environmentally labeled food in their choices (Peschel, Grebitus, Steiner, \& Veeman, 2016).

The current results are also in agreement with a recent meta-analytic study demonstrating that, in organic, credence attributes such as health, safety, nutrition, quality, environment, animal welfare, and production practices, are valued more than search and experience attributes (Massey, O'Cass, \& Otahal, 2018). For example, for issues related to animal welfare, public mechanisms (including social media engagement) that engage and empower the consumer and that reconnect consumers directly with primary producers are likely to be important (Regan, Henchion, \& McIntyre, 2018). In agreement with this, Akaichi, Glenk, and Revoredo-Giha (2019) have observed that the demand for organic animal products could be improved not only by selling its supposed superiority in terms of sustainability but also by promoting its advantages in terms of other attributes that are known to be highly valued by consumers such as animal welfare and nutritional content.

Despite the high sample size of the survey, some minor constraints may be found in this study. Firstly, it was not designed as a conjointchoice experiment and thus it did not allow ranking the different WTP for each credence attribute. Secondly, the methodology of on-line questionnaires used and the snowball dispersion could lead to some biases. In this sense, some parameters of the results indicated a bias to higher levels of education in the sample than in the overall population 
(58.2\% in Spain and 46.9\% Portugal; MECD, 2017). This may have increased their concern about credence attributes of pork, but the conclusions of the study are not altered. In fact, the main socio-demographics (age structure, gender and household characteristics) of the sample used were fairly good in representing the average consumer in that region.

\section{Conclusions}

The hypothesis that consumers' culinary skills would shift their attitudes towards niche pork was not supported. However, it was proven that credence cues of pork claiming health issues (absence of antibiotics and hormone residues) defined the WTP for niche pork (coming from pigs raised on outdoor paddocks and/or specifically certified organic pork) in these three country regions. In Northern Portugal, there was also a gender segmentation of WTP for organic pork, as women expressed higher WTP than men.

These results can be helpful for niche pork producers (outdoor husbandry and/or certified organic) to design marketing policies focused on perceived quality attributes (outdoor housing conditions improving animal welfare and/or organic management with minimum use of medication) rather than targeted at specific consumer segments based on food-related lifestyles. It is highlighted that consumers, irrespective of culinary skills, seek additional requirements for the pork value chain, which has to fulfill the functions of delivering both meat and more extrinsic cues in label information.

\section{Acknowledgements}

The authors express appreciation to all the colleagues who help launching of this survey questionnaire to their personal and professional contacts. G. Ripoll and A. Teixeira are members of the MARCARNE network, funded by CYTED (ref. 116RT0503).

\section{References}

Abrams, K. M., Meyers, C. A., \& Irani, T. A. (2010). Naturally confused: consumers' perceptions of all-natural and organic pork products. Agriculture and Human Values, 27, 365-374.

Akaichi, F., Glenk, K., \& Revoredo-Giha, C. (2019). Could animal welfare claims and nutritional information boost the demand for organic meat? Evidence from non-hypothetical experimental auctions. Journal of Cleaner Production, 207, 961-970.

Alvarez-Rodriguez, J., Villalba, D., Cubilo, D., Babot, D., \& Tor, M. (2016). Organic practices and gender are effective strategies to provide healthy pork loin. Journal of Integrative Agriculture, 15, 608-617.

Angulo, A. M., \& Gil, J. M. (2007). Risk perception and consumer willingness to pay for certified beef in Spain. Food Quality and Preference, 18, 1106-1117.

Angulo, A. M., Gil, J. M., \& Tamburo, L. (2005). Food safety and consumers' willingness to pay for labelled beef in Spain. Journal of Food Products Marketing, 11(3), 89-105.

Banovic, M., Grunert, K. G., Barreira, M. M., \& Fontes, M. A. (2010). Consumers' quality perception of national branded, national store branded, and imported store branded beef. Meat Science, 84, 54-65.

Bernués, A., Ripoll, G., \& Panea, B. (2012). Consumer segmentation based on convenience orientation and attitudes towards quality attributes of lamb meat. Food Quality and Preference, 26, 211-220.

Borgogno, M., Favotto, S., Corazzin, M., Cardello, A. V., \& Piasentier, E. (2015). The role of product familiarity and consumer involvement on liking and perceptions of fresh meat. Food Quality and Preference, 44, 139-147.

Carpentier, A., \& Latouche, K. (2005). French consumers' and citizens' concern: Which willingness to pay for 'green pork'? Paris: International workshop on green pork production17-18 May 25-27.

Casini, L., Boncinelli, F., Contini, C., Gerini, F., Scozzafava, G., \& Alfnes, F. (2019) Heterogeneous preferences with respect to food preparation time: Foodies and quickies. Food Quality and Preference, 71, 233-241.

Chamorro, A., Miranda, F. J., Rubio, S., \& Valero, V. (2012). Innovations and trends in meat consumption: An application of the Delphi method in Spain. Meat Science, 92 $816-822$

de Boer, J., Schösler, H., \& Aiking, H. (2017). Towards a reduced meat diet: Mind set and motivation of young vegetarians, low, medium and high meat-eaters. Appetite, 113 387-397.

Dransfield, E., Ngapo, T. M., Nielsen, N. A., Bredahl, L., Sjödén, P. O., Magnusson, M., Nute, G. R. (2005). Consumer choice and suggested price for pork as influenced by its appearance, taste and information concerning country of origin and organic pig production. Meat Science, 69, 61-70.

D'Souza, D. N., Cleary, D., \& Hewitt, R. J. E. (2017). Consumers want pork with 'adjectives'. Animal Production Science, 57, 2331-2338.

European Commission (2015). Study on information to consumers on the stunning of animals. Food chain evaluation consortium (FCEC), Brussels.

European Commission (2015b). Prospects for EU meat markets 2015-2025. EU agricultural outlook conference, 1-2 December 2015.

Eurostat. Organic farming statistics. (2018). http://ec.europa.eu/eurostat/ Accessed 22 July 2018.

FiBL (2017). European organic market data. Switzerland: Research Institute of Organic Agriculture, FiBL, Frick2015.

Font-i-Furnols, M., Tous, N., Esteve-Garcia, E., \& Gispert, M. (2012). Do all the consumers accept marbling in the same way? The relationship between eating and visual acceptability of pork with different intramuscular fat content. Meat Science, 91, $448-453$.

Gencat (2015). Barómetro de Percepción y Consumo de los Alimentos Ecológicos. Generalitat de Cataluña. (Spain).

Grunert, K. G. (2006). Future trends and consumer lifestyles with regard to meat consumption. Meat Science, 74, 149-160.

Grunert, K. G., Skytte, H., Esbjerg, L., Poulsen, C. S., \& Hviid, M. (2002). Dokumenteret kødkvalitet (MAPP project paper no. 2-02). Aarhus: Aarhus school of business.

Grunert, K. G., Sonntag, W. I., Glanz-Chanos, V., \& Forum, S. (2018). Consumer interest in environmental impact, safety, health and animal welfare aspects of modern pig production: Results of a cross-national choice experiment. Meat Science, 13, 123-129.

Hoek, A. C., Luning, P. A., Stafleu, A., \& de Graaf, C. (2004). Food-related lifestyle and health attitudes of Dutch vegetarians, non-vegetarian consumers of meat substitutes, and meat consumers. Appetite, 42, 265-272.

INE. Dados Estatísticos Portugal. Instituto Nacional de Estatística (2018). (https://www. ine.pt/ Accessed 22 July 2018).

INE. Información estadística. Instituto Nacional de Estadística. (2018).(http://www.ine. es/ Accessed 22 July 2018)

Lagerkvist, C. J., \& Hess, S. (2011). A meta-analysis of consumer willingness to pay for farm animal welfare. European Review of Agricultural Economics, 36(1), 55-78.

Laurent, G., \& Kapferer, J. N. (1985). Measuring consumer involvement profiles. Journal of Marketing Research, 41-53.

MAPA (2018a). Informe del consumo de alimentación en España. Ministerio de Agricultura, Pesca y Alimentación. (Spain).

MAPA (2018b). Estudio de la cadena de valor y formación de precios del sector de la carne de cerdo de capa blanca. Observatorio de Precios de los alimentos: Ministerio de Agricultura, Pesca y Alimentación. (Spain).

MAPAMA (2017). Caracterización de compradores de productos ecológicos en canal especializado. Ministerio de Agricultura y Pesca, Alimentación y Medio Ambiente. (Spain).

María, G. A. (2006). Public perception of farm animal welfare in Spain. Livestock Science, 103, 250-256.

Massey, M., O'Cass, A., \& Otahal, P. (2018). A meta-analytic study of the factors driving the purchase of organic food. Appetite, 125, 418-427.

MECD (2017). Panorama de la educación. Indicadores de la OCDE 2017. Ministerio de Educación, Cultura y Deporte. (Spain).

Mueller, S., Lockshin, L., \& Louviere, J. J. (2010). What you see may not be what you get: Asking consumers what matters may not reflect what they choose. Marketing Letters, $21,335-350$.

Ngapo, T. M., Dransfield, E., Martin, J. F., Magnusson, M., Bredahl, L., \& Nute, G. R. (2004). Consumer perceptions: Pork and pig production. Insights from France, England, Sweden and Denmark. Meat Science, 66, 125-134.

Ngapo, T. M., Martin, J. F., \& Dransfield, E. (2007). International preferences for pork appearance: 1. Consumer choices. Food Quality and Preference, 18, 26-36.

Ngapo, T. M., Martin, J. F., \& Dransfield, E. (2007b). International preferences for pork appearence: II. Factors influencing consumer choice. Food Quality and Preference, 18, 139-151.

Peschel, A. O., Grebitus, C., Steiner, B., \& Veeman, M. (2016). How does consumer knowledge affect environmentally sustainable choices? Evidence from a crosscountry latent class analysis of food labels. Appetite, 106, 78-91.

Pohjolainen, P., Tapio, P., Vinnari, M., Jokinen, P., \& Räsänen, P. (2016). Consumer consciousness on meat and the environment - exploring differences. Appetite, 101, $37-45$.

Regan, Á., Henchion, M., \& McIntyre, B. (2018). Ethical, moral and social dimensions in farm production practices: A segmentation study to assess Irish consumers' perceptions of meat quality. Irish Journal of Agricultural and Food Research, 57, 9-14.

Resano, H., Perez-Cueto, F. J. A., De Barcellos, M. D., Veflen-Olsen, N., Grunert, K. G., \& Verbeke, W. (2011). Consumer satisfaction with pork meat and derived products in five EU countries. Appetite, 56(1), 167-170.

Resurrección, A. V. A. (2003). Sensory aspects of consumer choices for meat and meat products. Meat Science, 66, 11-20.

Sanjuán, A. I., Resano, H., Zeballos, G., Sans, P., Panella-Riera, N., Campo, M. M. Santolaria, P. (2012). Consumers' willingness to pay for beef direct sales. A regional comparison across the Pyrenees. Appetite, 58(3), 1118-1127.

Scholderer, J., Nielsen, N. A., Bredahl, L., Claudi-Magnussen, C., \& Lindahl, G. (2004). Organic pork: Consumer quality perceptions. Project paper no 02/04. (Aarhus).

Sepúlveda, W., Maza, M. T., \& Mantecón, A. R. (2008). Factors that affect and motivate the purchase of quality-labelled beef in Spain. Meat Science, 80, 1282-1289.

Sørensen, E., Grunert, K. G., \& Nielsen, N. A. (1996). The impact of product experience, product involvement and verbal processing style on consumers cognitive structures with regard to fresh fish. MAPP working paper no. 42. Aarhus: The Aarhus School of Business.

Vander Naald, B., \& Cameron, T. A. (2011). Willingness to pay for other species' wellbeing. Ecological Economics, 1-11.

Verbeke, W., Pérez-Cueto, F. J. A., de Barcellos, M. D., Krystallis, A., \& Grunert, K. G. (2010). European citizen and consumer attitudes and preferences regarding beef and 
pork. Meat Science, 84, 284-292.

Verbeke, W., \& Vackier, I. (2004). Profile and effects of consumer involvement in fresh meat. Meat Science, 67, 159-168.

Wägeli, S., Janssen, M., \& Hamm, U. (2016). Organic consumers' preferences and willingness-to-pay for locally produced animal products. International Journal of
Consumer Studies, 40, 357-367.

Wang, J., Ge, J., \& Ma, Y. (2018). Urban Chinese consumers' willingness to pay for pork with certified labels: A discrete choice experiment. Sustainability, 10, 603.

Yeung, R. M. W., \& Morris, J. (2001). Food safety risk: Consumer perception and purchase behaviour. British Food Journal, 103(3), 170-186. 